\title{
Proteomic evaluation of potenciated sulfa treatment on gilthead sea bream (Sparus aurata L.) liver
}

\author{
VARÓ, I1;2*; RIGOS, G3; NAVARRO, J.C2; DEL RAMO, J1; CALDUCH-GINER, J2 ; HERNÁNDEZ, \\ A 1 ; PERTUSA, J1;TORREBLANCA, $\mathrm{A}^{1}$
}

1 Department of Functional Biology, Faculty of Biological Sciences, University of Valencia.Dr. Moliner, 50, 46100 Burjassot (Valencia, Spain).

${ }^{2}$ Instituto de Acuicultura de Torre de la Sal (CSIC), 12595 Ribera de Cabanes, Castellón (Spain).

3 Hellenic Centre for Marine Research (HCMR)". Hellenic Centre for Marine Research, Aghios Kosmas 16610, Ellinikon, ATTIKI (Greece).

Keywords: Proteomics, 2D-DIGE, sulfadiazine, trimethoprim, gilthead sea bream, mass spectrometry (MS)

\section{Abstract}

Potentiated sulfa drugs are a combination of sulfonamides and pyrimidine potentiators, such as trimethoprim. They are currently used against bacterial pathogens in Mediterranean marine fish farming, including gilthead sea bream (Sparus aurata). The present work aimed studying the potential hepatotoxicity of a combination of sulfadiazine (SDZ) and trimethoprim (TMP) in gilthead sea bream juveniles after oral administration, at the recommended ratio of 5:1 (SDZ/TMP), for 10 days. Difference Gel Electrophoresis Technology (DIGE) coupled with MS was used to identity possible markers of hepatotoxicity of this treatment. The results obtained show significant changes in the expression of 41 proteins by treatment $(p \leq 0.02)$. Among these proteins, 14 increased in abundance, and 27 decreased respect to the control group. Spots showing differential expression respect to the control were identified by PMF and/or LC-MS/MS and database research. Proteins like apolipoprotein A-I and fatty acid binding protein (lipid metabolism and transport, and antioxidant role), phosphogucomutase 1 (carbohydrate metabolism), elongation factor 1-alpha (protein biosynthesis and antioxidant role), mitochondrial aldehyde dehydrogenase (oxidation regulation activity and antioxidant role), ypbc-32-D06 (aminotransferases), were differentially expressed in treated fish. These proteins have not been associated before to potentiated sulfa effect; however, they are frequently found expressed differentially as a characteristic cellular/tissue stress response under different experimental conditions, making difficult their use as specific biomarkers for this treatment. 


\section{Introduction}

It is known that gilthead sea bream (Sparus aurata) is an economically very valuable fish species in the Mediterranean. Bacterial outbreak is the major cause of fish diseases and mortalities in Mediterranean cage fish farming (Rigos and Troisi 2005; Rigos and Katharios 2009), causing important losses. The main species causing important bacterial infections in gilthead sea bream are Vibrio anguillarum serotype $1 \mathrm{~b}$, and Photobacterrium damsela subsp. piscida (formerly Pausterella). Disease outbreaks in aquaculture are normally confronted with mass therapy, usually orally administered via incorporation of drugs into the feed. Antibacterial agents such as sulfonamides have been used to treat and control bacterial diseases in cultured fish for decades, essentially because of their low cost and efficacy in common infections. Sulfonamides mainly represented by sulfadiazine (SDZ) are a large range of structurally related synthetic compounds that are derivatives of sulphanilamide. Nowadays, sulfonamides are used in combination with pyrimidine potentiators or diaminopyrimidines such as trimethoprim (TMP) or ormetoprim (OMP), and are frequently called potentiated sulfonamides or, simply, potentiated sulfa. They have a broad spectrum of bacterial activity, and their combined efficacy is greater that the sum of the two separate drugs. This is because the sulfonamides are structural analogues and competitive antagonists of para-aminobenzoic acid (PABA). As such, they block normal bacterial use of PABA for the synthesis of dihydrofolic acid (folic acid), and the particular pyrimidine potentiators (TMP or OMP) used in combination, inhibit the next enzyme in the sequence (dihydrofolate reductase) to prevent the formation of tetrahydrofolic acid (folinic acid), which is required for the synthesis of DNA. This two inhibitory actions in the same pathway produce a bactericidal rather than bacteriostatic effect. Folic acid is not synthetized in fish, but it is instead a dietary requirement. This allows for selective toxicity to bacterial cells over fish cells.

Currently, potentiated sulfa are regularly used against bacterial infections in Mediterranean euryhaline fish farming (Rigos and Troisi, 2005), and the combination sulfadiazine and trimethoprim (SDZ/TMP) at a ratio of $5: 1$ is one of the most used treatments in Mediterranean aquaculture, although there are not specific data on the pharmacokinetic properties of sulfadiazine and trimethoprim. The recommended dose in fish is 25 and $5 \mathrm{mg} \mathrm{kg}^{-1}$ fish for SDZ and TMP respectively, for $5-10$ days presented on medicated food (Scott 1993; EMEA 1997). 
Previous studies on fish have shown that potentiated sulfa is rapidly absorbed and distributed throughout body fish tissues after oral administration, although there are differences in the comportment of the two antibiotics (Horsberg et al. 1997; Samuelsen et al. 1997; Kosoff et al. 2007). In Atlantic salmon (Salmo salar) held in seawater, the pharmacokinetics of SDZ/TMP after oral administration is fitted to onecompartment model. TMP is absorbed from the intestine quickly and completely and the peak plasma concentration (Tmax) is reached in $12 \mathrm{~h}$, whereas SDZ is absorbed slowly and the Tmax is found $24 \mathrm{~h}$ post administration, with a bioavailability of $100 \%$ for TMP and 46\% for SDZ (Hormazabal and Rogstad 1992; Horsberg et al. 1997). TMP concentrations are higher in tissues that in plasma, while SDZ is found at higher concentration in plasma for much longer time, and it is distributed slowly and uniformly through the tissues and body fluids. Both antibiotics have been shown to accumulate in tissues such as plasma, muscle, liver, skin and the uveal track of the eye, and TMP has also been shown to bind to tissues containing melanin (Bergsjo et al. 1979; Hormazabal and Rogstad 1992). The accumulation of other diaminopyrimides (such as OMP) in fish has been related to its binding to specific proteins including probably those involved in haematopoiesis, that are located in head kidney and spleen; and OMP and/or metabolites have been detected in all tissues relative to plasma, mainly in the excretory tissues (i.e. liver and trunk kidney), head kidney, spleen, muscle and skin (Pakas et al. (1990). In fish sulfonamides are metabolized primarily in the liver, but metabolism also occurs in other tissues, and acetylation and glucuronidation are the major pathways. Biliary excretion is the main route of elimination of both drugs, although renal excretion has been also reported in fish (Bergsjø et al., 1979).

In general the toxicity related with sulfonamides in both human and animals, is crystalluria (renal toxicity); however, the lower doses of sufonamide used in the potentiated sulfa combinations makes nephrotoxicity less probable to occur than with sulphonamide administrated alone (The United States Pharmacological Convention, INC, 2007). Although there are not many reports on the specific toxic side effects of potentiated sulfa in fish, different immunomodulatory effects have been associated with the use of this antibacterial drugs. Enhanced leucocyte proliferation in vitro but not in vivo has been shown in rainbow trout (Oncorhynchus mykiss) after treatment with different sulfonamides combined with TMT (Grondel et al. 1986; Lunden and Bylund 2002). Saglam and Yonar (2009) found decreases in haematological (haematocrit and leucocrit values, and haemoglobin), and immunological parameters (total plasma protein and total Ig levels) in the same fish species treated with sulfamerazine. This study also showed that sulfamerazine had an immunosuppressive effect on fish because of a decrease in NBT(+) cell levels. By contrast, Lunden and Bylund (2000) 
did not find neither negative effect on the immune system of rainbow trout after oral administration of SDZ/TMP in a ratio 5:1, nor in the survival. Yildiz and Altunay (2011) reported the effect of sulfamethoxazole and TMP on the physiologial stress and immunological response of gilthead sea bream and sea bass (Dicentrarchus labrax). This study concluded that the treatment produces the activation of the classical acute stress response with a transient increase in plasma cortisol and glucose after treatment, and a decreased during the recovery period, for both species. Regarding to innate immune markers measured (haematocrit, lysozyme activity, C-reactive protein and ceruloplasmin), the authors concluded that it is difficult to consider the inmunosuppression in gilthead sea bream and sea bass.

There are not previous studies about the capacity of the SDZ/TMP to produce liver injury at molecular level in cultured euryhaline fish after a routinely antibacterial treatment. At present, proteomic technology approach has the potential to find the protein alterations indicative of the mode of action of chemicals without previous knowledge of their mode of action, and it may be useful to discover new biomarkers of hepatotoxicity in animals, including fish (Varó et al., 2010). Thus, the present study aimed at testing the potential hepatotoxicity effects of SDZ/TMP on gilthead sea bream juveniles after oral administration at the recommended ratio of $5: 1$ for 10 days. The liver was investigated as the principal target of toxicity due to the role of this organ in energetic and xenobiotic metabolism of drugs, such as SDZ/TMP. To this end the effect of this treatment was evaluated thought a proteomic approach, using 2-D differential gel electrophoresis (2D-DIGE), and proteins of interest were identified by mass spectrometry analysis and database search. Unveiling of the liver protein pattern could give useful insight to detect early hepatotoxicity effects at molecular level in response to a routinely (standard) SDZ/TMP treatment used in the control of bacterial fish diseases. The proteomic results were confirmed by real-time RT-PCR of selected proteins, and the study was also complemented with the histological analysis of liver.

\section{Materials and Methods}

\subsection{Animals and sample preparation}

Juveniles of gilthead seabream ( $S$. aurata) $(35 \pm 9 \mathrm{~g})$ were purchased from a local commercial aquaculture farm (Acuicola Marina SL, Burriana, Castellón, Spain), and kept in the facilities of the aquarium plant of the University of Valencia. Fish were placed in several $2000 \mathrm{~L}$ fibreglass tanks (120 fish per tank) filled with seawater (32 
$\%$, supplied with continuous aeration under room temperature $\left(19 \pm 0.5^{\circ} \mathrm{C}\right)$ in a closed circuit, and acclimated for 1 week before starting the experiment.

After acclimation, the test fish groups were fed medicated dry food pellet with SDZ/TMP at the recommended concentration ratio of $5: 1$, equivalent to a dose of 30 $\mathrm{mg} \mathrm{Kg}^{-1}$ fish $\mathrm{d}^{-1}$, for 10 days (daily feeding ratio $1 \%$ body weight). The control fish groups were administered unmedicated pelleted feed at the same feeding schedule. The experimental feeds were made at the Fish Nutrition and Pathology Laboratory, Institute of Aquaculture, of the Hellenic Center for Marine Research in Athens (Greece). Commercial feed (Biomar) with the following composition: fish meal (35\%), soya bean meal $(20 \%)$, wheat meal $(15 \%)$, rapeseed meal $(2.7 \%)$, wheat gluten $(5 \%)$, corn gluten $(10 \%)$, fish oil $(13 \%)$, premix $(0,3 \%)$, were grounded, mixed with the drug, and prepared as dry pellets suitable for the size of the fish. The same basic procedure was followed for the preparation of the unmedicated diet.

At the end of treatment, eight fish from each experimental group were anaesthetized with clove oil $\left(20 \mathrm{mg} \mathrm{L}^{-1}\right)$ and sacrificed before livers being dissected out. The samples were quickly frozen in liquid nitrogen and stored at $-80^{\circ} \mathrm{C}$ until analysed. Handling of the fish was done according to national and institutional regulations for animal experimentation.

\subsection{D difference gel electrophoresis (2D-DIGE): protein sample preparation and protein labelling}

Liver tissues used in the 2D-DIGE analyses were processed as previously described (Varó et al., 2010). Briefly, individual livers were homogenized with the aid of the grinding kit system (General Electric Healthcare) in nine volumes of DIGE buffer (7 M urea, $2 \mathrm{M}$ thiourea, 4\% CHAPS, $30 \mathrm{mM}$ Tris) and $100 \mu \mathrm{L} \mathrm{mL}^{-1}$ of the Complete Mini (Roche) as protease inhibitor. The solubilized proteins were separated from nonsolubilized cellular components by centrifugation $(20,000 \mathrm{~g} \times 20 \mathrm{~min})$. Proteins present in the supernatants were precipitated using the 2D Clean-up kit (GE Healthcare, Uppsala, Sweden) according to the manufacturer's instructions and resolublized in DIGE buffer. The pH of protein extract was adjusted to 8.5 by adding $50 \mathrm{mM} \mathrm{NaOH}$, and protein concentration was determined using the Bradford Biorad Protein Assay (RcDc kit) with BSA (bovine serum albumin) as standard.

Liver proteins extracted from control $(n=8)$ and treated $(n=8)$ fishes were randomly labelled with Cy3 or Cy5. For DIGE minimal labelling, $50 \mu \mathrm{g}$ of protein sample was mixed with 400 pmol CyDye (GE healthcare) by vortexing and incubated on ice in the dark for $30 \mathrm{~min}$. The labelling reaction was stopped by the addition of $1 \mu \mathrm{L} 10 \mathrm{mM}$ 
lysine followed by incubation on ice for a further $10 \mathrm{~min}$. The internal standard sample was prepared by pooling $25 \mu \mathrm{g}$ of protein from each liver sample studied, and by labelling by Cy 2 as described above. Combinations of a Cy3 and a Cy5 labelled sample were then mixed with Cy2-labeled internal standard, and DTT (65 mM final concentration) and ampholytes ( $1 \%$ final concentration, $\mathrm{pH}=3-10$ ) were added to the mixture before running the first dimension.

\subsection{Gel electrophoresis (2D-DIGE gel) and image capture}

The 16 liver protein samples were analysed on a total of 8 analytical 2-D gels. IPG strips (24 cm, pH = 3-11NL) were rehydrated in $8 \mathrm{M}$ urea, 4\% CHAPS, DeStreak (12 $\mu \mathrm{L} \mathrm{mL} \mathrm{L}^{-1}$ ), and ampholytes ( $1 \%$ final concentration, $\mathrm{pH}=3-10$ ) overnight at room temperature. Cy-labelled samples were applied onto IPG rehydrated strips via anodic cup loading, and IEF was performed on a Ettan IPGphor II horizontal electrophoresis system (Amersham Biosciences) at $20^{\circ} \mathrm{C}$ using the following program: step 1:300 $\mathrm{V} 4$ h, gradient to $1000 \mathrm{~V} 6 \mathrm{~h}$, gradient to $8000 \mathrm{~V} 3 \mathrm{~h}$; step 2: $8000 \mathrm{~V}$ until reached $32000 \mathrm{~V}$ h.

After IEF, the strips were reduced in equilibration buffer (Tris $50 \mathrm{mM}$, urea $6 \mathrm{M}$ and glycerol $30 \%(\mathrm{v} / \mathrm{v}), 2 \%$ SDS $(\mathrm{w} / \mathrm{v}))$ containing $2 \%$ DTT, for $15 \mathrm{~min}$ at room temperature; followed by alkylation in equilibration buffer containing $2.5 \%$ iodoacetamide, for $15 \mathrm{~min}$ at room temperature. Then, the strips were transferred to the second dimension $12.5 \%$ acrylamide SDS-PAGE gels $(25 \mathrm{~cm} \times 21 \mathrm{~cm} \times 1 \mathrm{~mm})$ made between low fluorescence glass plates, and overlaid with $0.5 \%$ low melting agarose. The gels were run in Ettan Dalt Six Unit (GE Healthcare) electrophoresis system at $2 \mathrm{~W}$ per gel for $1 \mathrm{~h}$ and $15 \mathrm{~W}$ per gel for $6 \mathrm{~h}$.

After electrophoresis, the 2-D gels were scanned directly in a Typhoon ${ }^{\mathrm{TM}} 9400$ Variable Mode Imager to visualize the labelled proteins. Excitation and emission wavelengths were chosen specifically for each of the dyes according to manufacturer's recommendations (GE Healthcare).

\subsection{Data analysis}

Fluorescence images were analyzed using DeCyder ${ }^{\mathrm{TM}}$ V. 6.5 and DeCyder ${ }^{\mathrm{TM}}$ EDA software V.1.0 as described in Varó et al. (2010). Briefly, the intra-gel images were processed by DeCyder-DIA (Differential In-gel Analyses) software module to co-detect and differentially quantify the protein spots in the images, with the threshold set to 2 standard deviations. Then, the DeCyder-BVA (Biological Variation Analysis) was 
applied to inter-gel matching, and differences in average ratios of protein expression were analysed by the Student's t- test ( $p \leq 0.02)$. Finally, EDA software was used for multivariate statistical analysis of data. Principal Components Analysis (PCA) was carried out following the nonlinear iterative partial least squared method, including only proteins present in at least $80 \%$ of the spot maps and applying a t-test filter $(p \leq 0.02)$. A hierarchical cluster analysis was performed using the same protein selection criteria.

\subsection{Protein identification by mass spectrometry (MALDI, MS/MS) analysis}

Proteins of interest were manually excised from analytical gels and digested with sequencing grade trypsin (Promega) as described elsewhere (Shevchenko et al. 1996), and subject to PMF (MALDI) and/or LC-MS/MS analyses.

The digestion mixture was dried in a vacuum centrifuge, resuspended in $7 \mu \mathrm{L}$ of $0.1 \%$ TFA (trifluoroacetic acid, Sigma), and $1 \mu \mathrm{L}$ was spotted onto the MALDI target plate. After the droplets were air-dried at room temperature, $0.5 \mu \mathrm{L}$ of matrix $(5 \mathrm{mg} \mathrm{mL}$

${ }^{1}$ CHCA ( $\alpha$-cyano-4-hydroxycinnamic acid, Sigma) in 0.1\% TFA-ACN/H2O $(1: 1, \mathrm{v} / \mathrm{v})$ was added and allowed to air-dry at room temperature. The resulting 576 fractions were analyzed in a 4700 Proteomics Analyzer (Applied Biosystems, Foster City, USA) in positive reflection mode (2000 shots every position). Five of the most intense precursors (according to the threshold criteria: minimum signal-to-noise: 10, minimum cluster area: 500, maximum precursor gap: 200 ppm, maximum fraction gap: 4) were selected for every position for the MS/MS analysis. And, MS/MS data was acquired using the default $1 \mathrm{kV}$ MS/MS method.

The MS and MS/MS information was sent to MASCOT via the GPS software (Applied Biosystems). Database search on Swiss-Prot and NCBI databases was performed using MASCOT search engine (Matrix-Science). Searches were done with tryptic specificity allowing one missed cleavage and a tolerance on the mass measurement of $100 \mathrm{ppm}$ in MS mode and $0.8 \mathrm{Da}$ for MS/MS ions. Carbamidomethylation of Cys was used as a fixed modification and oxidation of Met and deamidation of Asn and GIn as variable modifications.

The samples without a positive identification were analysed by LC-MS/MS. Peptide separation by LC-MS/MS was performed using an Ultimate nano-LC system (LC Packings) and a QSTAR XL Q-TOF hybrid mass spectrometer (MDS SciexApplied Biosystems). Samples $(5 \mu \mathrm{L})$ were delivered to the system using a FAMOS autosampler (LC Packings) at $40 \mu \mathrm{L} \mathrm{min}^{-1}$, and the peptides were trapped onto a PepMap C18 pre-column (5 mm $300 \mu$ m i.d.; LC Packings). Peptides were then eluted onto the PepMap C18 analytical column (15 cm $75 \mu \mathrm{m}$ i.d.; LC Packings) at $200 \mathrm{~nL}$ 
$\min ^{-1}$ and separated using a 55 min gradient of $15-50 \%$ CAN. The QSTAR XL was operated in information-dependent acquisition mode, in which a 1-s TOF MS scan from 400-2000 m/z, was performed, followed by 3-s product ion scans from 65-2000 m/z on the three most intense doubly or triply charged ions.

The MS/MS information was sent to MASCOT via the MASCOT DAEMON software (Matrix-Science). The search parameters were defined as for MS-MS/MS analysis.

\subsection{Quantitative RT-PCR of selected proteins}

Total RNA was prepared from the same liver used for the proteomic analysis using the RNAspin MiniRNA isolation kit (GE HealthCare), according to the manufacturer's instructions, and stored at $-80{ }^{\circ} \mathrm{C}$. The purity and quantity of extracted RNA were measured using the Experion System (Bio-Rad). Two hundred ng of total RNA was reverse transcribed into cDNA using the High-Capacity cDNA reverse transcription kit (Applied Biosystems), with a final reaction volume of $20 \mu \mathrm{L}$. The RT conditions were: $10 \mathrm{~min}$ at $25^{\circ} \mathrm{C}, 120 \mathrm{~min}$ at $37^{\circ} \mathrm{C}$ and $5 \mathrm{sec}$ at $85^{\circ} \mathrm{C}$. The cDNA samples were stored at $-20^{\circ} \mathrm{C}$ until use.

Transcript measurements were made by real-time PCR using an iCycler IQ Real-time Detection System (Bio-Rad, Hercules, CA, USA), following the procedure described by Calduch-Giner et al. (2003) RT reactions were conveniently diluted and $7.5 \mu \mathrm{L}$ were used for PCR reactions in a $25 \mu \mathrm{L}$ volume. Each PCR-well contained a SYBR Green Master Mix (Bio-Rad) with specific primers at a final concentration of 0.9 $\mu \mathrm{M}$ (see Table 1). The housekeeping gene $\alpha$-tubulin was used as an internal control to normalize the data and the efficiency of PCR reactions for target and reference genes varied between $88 \%$ and $95 \%$, respectively. The dynamic range of standard curves spanned five orders of magnitude, and the amount of product in a particular sample was determined by interpolation of the cycle threshold $(\mathrm{Ct})$ value. The specificity of reaction was verified by analysis of melting curves. Fluorescence data acquired during the extension phase were normalized to $\alpha$-tubulin by the delta-delta method (Livak and Schmittgen, 2001), using data in control fish as reference values. No changes in $\alpha$ tubulin expression were found in response to treatment.

The difference in gene expression levels between control and treated fish was calculated by two-tailed independent Student t-test using SPSS statistics software v 17.0. A $p$ value $\leq 0.05$ was considered statistically significant. 


\subsection{Histology}

For histological analyses subsamples from the same liver used for the proteomic study were processed following standard procedures. The samples were immediately fixed in buffered formalin at $4^{\circ} \mathrm{C}$ for $24 \mathrm{~h}$. Then, they were transferred to $70 \%$ alcohol and kept there until processing. Finally, samples were dehydrated in alcohol, wax-embedded, sliced into $6 \mu \mathrm{m}$ thick sections and stained with the hematoxylin and eosin technique for histological evaluation.

\section{Results}

A representative 2D-DIGE-gel image of the liver proteins profile from treated versus control fish is shown in Figure 1. Proteins over the range of $\mathrm{pH}$ applied in this experiment $(\mathrm{pH}=3-11 \mathrm{NL})$ and with a molecular weight from approximately 10 to 250 $\mathrm{kDa}$ were resolved, and 3994 spots in the master gel were detected using the DeCyder BVA software. Each protein spot was assigned an average ratio (i.e. change in expression level due to SDZ/TMP treatment) and $p$-value (t-student) to indicate the level of significance. Forty-one proteins were differentially expressed in the livers of the treated fish (standardized average volume ratio $\geq 1.3$, t-student $\leq 0.02$ ). Among these protein spots, 14 were up-regulated and 27 down-regulated by potentiated sulfa (SDZ/TMP) treatment. The positions of those differentially expressed protein spots in the 2D-DIGE are also shown in Figure 1. The PCA and hierarchical cluster analyses of data are shown in Figure 2. The PCA results obtained indicated that two components are enough to cluster the different experimental groups (control vs treated), with a clear separation in the first component (PC1) between them (Fig 2A). The pattern analyses showed a clustering in a hierarchical way, where protein maps corresponding to control group formed a cluster separated from those corresponding to the SDZ/TMP treated group (Fig 2B)

The 2D-DIGE analyses (spot $\mathrm{n}^{\circ}$, protein name, theoretical $\mathrm{MW} / \mathrm{pl}$, accession number, $\mathrm{p}$-value, and the average ratio) and the results of protein identification by PMF and/or LC-MS/MS and database research are listed in Table 2. Ten of these forty-one differentially expressed protein spots were successfully identified after database searching in the public access data bases and the in-house developed sea bream EST database (only spot 3850). Most of them correspond to protein sequences that have previously been described in fish. The rest of the protein spots differentially expressed were in too low amount of protein after in-gel trypic digestion to obtain a good peptide mass spectrum for identification using MASCOT search. Table 2 also shows the 
biological process involved, according to Gene Ontology (UniProtKB GO).

The analyses of biological processes of the identified proteins in terms of GO, revealed that the up-regulated proteins are related to carbohydrate metabolism (phosphogucomutase 1: PGM1, spot 1253), translational elongation activity (elongation factor 1-alpha: EF1 $\alpha$, spot 1597), and oxyreductase activity (mitochondrial aldehyde dehydrogenase: ALDH2, spot 1543). Another up-regulated spot (spot 1902) was identified in EST database as ypbc-32-D06 (Yellow perch control brain library Perca flavescens cDNA), which is associated with amino acid metabolic processes. As for the down-regulated spots, a first group of three down-regulated proteins is involved in the cholesterol metabolism/lipid transport (apolipoprotein A-I: apoA-I, spots 3076, 3993 and 3992). Another spot corresponds to a protein related with lipid transport (fatty acid binding protein FABP, spot 3850), and a last one to a binding protein (USCH1C-binding protein, spot 2223). Besides, potentiated sulfa treatment induced down-regulation in one protein of unknown function (spot 3762).

The relative transcript hepatic expression levels of PGM1, EF1 $\alpha, A L D H 2$, FABP, and Apo A-I are shown in Figure 3. The relative gene expressions apparently increase as a result of the potentiated sulfa treatment, even though there were not significant differences between control and treated fish $(p>0.05)$.

In the histological analyses structural or morphological differences were not observed between controls and potentiated sulfa treated livers, and no pathological alterations were found in the livers from fish treated with potentiated sulfa (Fig 4).

\section{Discussion}

Proteomic approach is an efficient method to screen for differences in protein expression as well as to identify new proteins in a particular tissue, which can be associated with specific conditions such as drug treatment, diseases or nutritional status. In this study, 2D DIGE analysis coupled with MS protein identification was performed in order to identify the hepatic proteins differentially expressed in response to standard potentiated sulfa treatment in gilthead sea bream. Although the same proteomic approach has been used to analyse the effects of ivermectin (antiparasitic drug) in this species (Varo et al. 2010), this is the first attempt of such approach to examine the potential hepatotoxicity of antibacterial drugs, such as SDZ/TMP in sea bream.

The 2D DIGE results showed that 41 spots were differentially expressed in response to SDZ/TMP treatment, and 10 of these were positively identified using MS/MS. The differences in the expression levels of 41 proteins allow discriminating 
treated fish from control fish according to the cluster analyses. Considering the changes in the liver proteome profile, together with the lack of hepatic damage, it is likely that this set of proteins indicates a transient or preliminary hepatotoxicity, and that these proteins could be considered as early PES (altered protein expression signatures) associated to SDZ/TMP treatment. This result is similar to our previous study on gilthead sea bream treated with ivermectin, where the changes in protein expression of 36 spots allowed to separate the medicated from the control group of fish, and thus, it was considered as a very early PES of ivermectin routine treatments for this species (Varó et al., 2010). Moreover, the fold changes found here in the protein spots were comparable to those obtained with invermectin.

Using PMF and/or LC-MS/MS and database research we were able to identify positively only 10 of the 41 proteins differentially expressed by SDZ/TMP treatment, because of identification of proteins unrepresented in databases from incomplete or non-sequenced organism remains challenging (Liska and Shevchenko 2003; Waridel et al. 2007). The proteins identified are involved in the metabolism of carbohydrates (PGM1), metabolism and transport of lipids (apoA-I, FABP), protein biosynthesis and binding (EF1 $\alpha$, USH1C-), oxidation regulation activity (ALDH2), as well as in amino acid metabolic process (ypbc-32-D06) (Table 2), in agreement with the metabolic role of the liver. It should be noted that these proteins are different to those differentially expressed by invermectin treatment, with the exception of apo A-I (Varó et al., 2010). However, these proteins have been previously identified in fish, highlighting the fact that most of them are similar or belong to some of the most frequently detected proteins in proteomic studies independently of the experimental conditions or tissue analysed (Wang et al. 2009).

In the present study apoA-I was down-regulated as result of SDZ/TMP treatment. This is the major component of high-density lipoprotein (HDL), which is known to be involved in reverse cholesterol transport from tissues to the liver, and in lipid metabolism. Moreover, apoA-I has been reported to play other roles in fish, related with antimicrobial activity (Johnston et al. 2008), innate immunity (Villarroel et al. 2007), or osmotic regulation (Chen et al. 2009). The apoA-I responsible for these functions, however, is more abundantly expressed in several other tissues such as epidermis, gills and intestinal mucosa, than in the liver. The same decreased expression of apoA-I was found in the liver of gilthead sea bream after 10 days ivermectin treatment at the recommended dose of $0.2 \mathrm{mg} / \mathrm{kg}$ fish (Varó et al., 2010). Again, similarly, reduced expression of apoA-I has been observed in fish liver when transferred from freshwater to brackish water (Chen et al., 2009), or when fed 3-thia fatty acids (Kleveland et al. 2006). Likewise, a decrease in apoA-I abundance was found in plasma and muscle of 
Atlantic salmon (Salmon salar) in response to crowding stress (Veiseth-Kent et al. 2010).

Another protein down-regulated in the treated fish was fatty acid binding protein (FABP). FABPs are members of the superfamily of lipid-binding proteins. The main role of all the FABP family members is regulation of fatty acid uptake and intracellular transport. They are involved in the transport and storage of lipids, as well as cholesterol and phospholipid metabolism (Chmurzynska 2006). Also, FABPs are related to metabolic and immune response pathways (Furuhashi and Hotamisligil 2008), and to antioxidant functions (Wang et al. 2005). Previous studies on fish have reported changes in the expression of liver FABP in response to stress. Wang et al. (2008) found in the liver of goldfish (Crassius auratus), that one of the two spots identified as FABP (paralogs) decreased, whereas the other increased in the stressful environment. Reduced expression of liver FABP in Senegalese sole (Solea senegalensis) affected by hyperoxia stress has been related to protein oxidative damages (Salas-Leiton et al. 2009). However, the increase in the level of liver FABP found in gilthead sea bream and Senegalese sole subjected to handling and crowing stress, was associated with an increase in lipid mobilization, in order to respond to the increased energetic requirements due to stress, as well as in preventing oxidative damage (Alves et al. 2010; Cordeiro et al. 2012).

The down regulation of apoA-I and FABP found in the liver of fish treated with SDZ/TMP suggests a reduction in lipid metabolism and transport, and probably in their capacity to protect liver from oxidative stress induced by xenobiotics like potentiated sulfa. This fact might be important in the development of fatty livers in potentiated sulfa treated fish after prolonged treatments or higher doses, since no alteration was found in the livers of treated fish, which is in agreement with previous studies involving other compounds like hydrazine and ivermectin (Waterfield et al. 1997; Kleno et al. 2004; Varo et al. 2010). In addition, in livers of FABP deficient mouse it has already shown a shift in lipid distribution in favour of cholesterol, cholesterol esters, and phospholipids, as well as potentiated hepatic cholesterol accumulation in cholesterol-fed females, supporting that liver FABP is involved in the physiological regulation of cholesterol metabolism, which is important for the maintenance of animal homeostasis (Martin et al. 2003; Martin et al. 2006).

Likewise, it was found that potentiated sulfa (SDZ/TMP) induced an upregulation of phosphoglucomutase 1 (PGM1). This is a protein related to carbohydrate metabolism, catalysing the reverse conversion of glucose 1-phosphate into glucose 6phosphate. An increase in hepatic PGM1 has been found in gilthead sea bream fed maslinic acid, indicating a stimulation of glycogen metabolism (Rufino-Palomares et al., 
2011). An up-regulation of PGM1 has also been obtained in fish as response to longterm anoxia (Wulff et al. 2008). Another study done on cytotrophoblasts, reported an increase in PGM1 as response to hypoxia (Hoang et al. 2001). Our results may suggest that the treatment with SDZ/TMP produce an activation of carbohydrate metabolism as classical stress response in fish, since glucose is required to cope with increased energy demand of stress responding tissues as liver. This is consistent with an increase in plasma glucose levels found in gilthead sea bream and sea bass exposed to a combination of sulfamethoxazole and TMP (Yildiz and Altunay 2011).

Another protein that increased in the liver of treated fish was elongation factor 1 -alpha $(E F 1 \alpha)$. This protein is very abundant in eukaryotes, comprising 1 to $10 \%$ of total cellular protein content. In gilthead sea bream EF1 $\alpha$ has an ubiquitous and uniform distribution in tissues (Nowell et al. 2000). This protein plays a central role in protein biosynthesis. It is the aminoacyl-transfer RNA binding factor in peptide chain elongation, as it promotes the GTP-dependent binding protein of aminoacyl-tRNA to the A-site of ribosomes during protein synthesis. In addition, EF1 $\alpha$ has been related to the mobilization of the ubiquitin-proteasome pathways and protein degradation (Buckley et al. 2006; Gonen et al. 1994) in the cell apoptosis process in response to oxidative stress (Chen et al. 2000; Duttaroy et al. 1998), as well as in response to thermal stress (Ibarz et al. 2010; Buckley et al. 2006). In the present study the overexpression of hepatic EF1 $\alpha$ found in fish treated may be related with a higher degree of liver protection from oxidative stress caused by potentiated sulfa (SDZ/TMP), since this protein is required for protein biosynthesis. This agrees with previous results demonstrating an increase in hepatic EF1 $\alpha$ associated to oxidative stress and apoptosis in gilthead sea bream as response to cold (Ibarz et al. 2010). An increase in gill EF1 $\alpha$ has also been shown in the goby (Gillichthys mirabilis) exposed to heat stress, and was related to the mobilization of the ubiquitin-proteasome pathways, whereas the repression of muscle EF1 $\alpha$ was linked to a minor need for ubiquitylation and degradation of damaged proteins in this tissue (Buckley et al. 2006).

An increase in mitochondrial aldehyde dehydrogenase (ALDH2) in the liver of treated fish was also observed. This protein belongs to the aldehyde dehydrogenase family (ALDHs), and has an oxidoreductase activity. The ALDH2 catalyses the conversion of acetaldehyde into acetic acid. This enzyme is known to play a major role in acetaldehyde oxidation in vivo (Vasiliou et al. 2000). In fish, previous studies showed ALDHs enzymes to be involved in detoxification processes (Nilsson 1988; Pretti et al. 2001). The increase in the levels of ALDH2 found in treated fish could reflect an increase in their capacity to process aldehydes and, therefore to protect the liver from 
oxidative stress. In fact, a down regulation of ALDHs enzymes in fish liver has been related to a diminution of the capacity to protect this organ from oxidative stress (Cordeiro et al. 2012), and also with a non-induction of detoxification processes (Rufino-Palomares et al. 2011).

We found an increase in the spot 1902 identified in EST database as ypbc-32D06 (Yellow perch control brain library Perca flavescens cDNA). A new search using BLASTx showed a sequence producing significant alignments of this EST with the protein annotation: PREDICTED: aspartate aminotransferase, cytoplasmic-like (AAT_like) (NCBI Reference Sequence: XP_003454182) described in tilapia (Oreochromis niloticus). AAT_like is a family that belongs to pyridoxidal phosphate (PLP)-dependent transaminase enzyme, and catalyses the reversible transfer of a $\alpha$ amino group between aspartate and glutamate and, as such, is an important enzyme in amino acid metabolism. Aspartate aminotransferase, like alanine aminotransferase, is a key enzyme in the protein to carbohydrate metabolism. It has a wide distribution in both mammalian and fish tissues (Eze 1983; Gaudet et al. 1975). The enzyme is found in the liver, heart, skeletal muscle, kidneys, brain, and red blood cells, and changes in aminotransferases activities are frequently used as biomarker to determine fish liver damage (De la Torre et al. 2005; Prashanth and Neelagund 2008; Inyang et al. 2010). The up-regulation of ypbc-32-D06 found in liver of treated fish may indicate the activation of aspartate aminotransferase enzyme, which could be suggesting an increased participation of proteins in the energy production during treatment, as described De Smet and Blust (2001) in carp (Cyprinus carpio) exposed to cadmium, since no morphological alterations were observed in the liver of fish treated with potentiated sulfa. In the same way, a down regulation of a mitochondrial precursor of aspartate aminotransferase found in gilthead sea bream under cold stress was related to a lower capacity for amino acid catabolism and interconversion in cold and fasting fish (lbarz et al. 2010).

The overexpression of theses proteins involved in energy production (PGM1 and $A L D H 2)$ and protein biosynthesis (EF1 $\alpha$ ) could be related to an increased energy demand to cope with the xenobiotic stress caused by potentiated sulfa treatment in order to maintain homeostasis, as well as with a stimulation of antioxidant defences.

In addition, analysis of mRNA coding for 4 of the proteins identified from those differentially expressed in control and treated fish did not reveal significant differences, although they showed higher values in treated fish. The lack of correlation found between mRNA expression and proteomic analysis is in agreement with the results of Wang et al (2008), who suggested that discrepancy between the abundance of cognate proteins and RNA molecules is frequently observed. 
In conclusion, this study provides a proteomic analysis of the liver protein expression in response to a routine 10 days potentiated sulfa treatment in gilthead sea bream. A set of 41 proteins was differentially expressed in response to treatment. These were able to separate medicated and control groups of fish, and may be considered as PES for possible hepatotoxicity of potentiated sulfa in this species. The liver proteins found to have different expression in treated fish are involved in several well-known processes related to metabolic stress, including amino acid, carbohydrate and lipid metabolism, as result of transient metabolic and energetic adjustments with a lack of liver injury, due probably to the short period of time of the potentiated sulfa treatment. These results highlight that the proteins identified are generally expressed differentially as characteristic cellular/tissue stress response under different experimental conditions, and their use as biomarkers for this treatment should be done with caution.

\section{Acknowledgements:}

This work was funded by projects GV06B-351 "Generalitat Valenciana" and CTM 200614279-CO2-01/MAR MEC-FEDER. This research was performed within the framework of a concerted action between Spain and Greece (HG-2004-0016). I. Varó was a recipient of a "Ramón y Cajal" contract at the University of Valencia from the "Ministerio de Educación y Ciencia (Spain)". DIGE analyses and MS identification were performed in the proteomics service of the "Principe Felipe" Research Centre (CIPF), Valencia (Spain), a members of ProteoRed (The Spanish Proteomics Network). We thanks to $\mathrm{M}^{\mathbf{a}}$ Angeles Gonzalez from IATS- CSIC for her technical help with Q-RT-PCR analysis; and Oreto Antúnez from Central Service for Experimental Research (SCSIE, University of Valencia) for her technical and data support in DIGE design. 


\section{Figure legends}

Fig. 1. Representative 2D-DIGE gel of soluble liver proteins extracted from gilthead sea bream (S. aurata). 3-10NL pH range were used for IEF. Protein spots differentially expressed and identified are numbered as in table 2. In green down-regulated spots and in red up-regulated spots.

Fig. 2. Multivariate analyses of liver proteomic data. (A) Principal Component Analysis (PCA) and hierarchical cluster analyses (B) of the proteins differentially expressed. PCA and the dendrogram after hierarchical analysis show a good separation of the spots maps corresponding to the different experimental groups (control in blue vs treated in red).

Fig. 3. Relative liver gene expression of PGM (phosphoglucomutase 1), EF (elongation factor 1-alpha), ALDH2 (mitochondrial aldehyde deshydrogenase), FABP (fatty acid binding protein), and apoA-I (apolipoprotein A-1) in control and potentiated sulfa treated fish. Values are means $\pm s d(n=4-6)$. Means were compared by t-test with a $p$ value of 0.05

Fig. 4. Histological sections from the liver of $(A)$ control and $(B)$ potentiated sulfa treated gilthead seabream (S. aurata) fish. 


\section{References}

Alves RN, Cordeiro O, Silva TS, Richard N, de Vareilles M, Marino G, Di Marco P, Rodrigues PM, Conceicao LEC (2010) Metabolic molecular indicators of chronic stress in gilthead seabream (Sparus aurata) using comparative proteomics. Aquaculture 299 (1-4):57-66. doi:10.1016/j.aquaculture.2009.11.014

Bergsjo T, Nafstad I, Ingebrigtsen K (1979) The distribution of 35S-sulfadiazine and 14C-trimethoprim in rainbow trout, Salmo gairdneri. Acta veterinaria Scandinavica 20 (1):25-37

Buckley BA, Gracey AY, Somero GN (2006) The cellular response to heat stress in the goby Gillichthys mirabilis: a cDNA microarray and protein-level analysis. Journal of Experimental Biology 209 (14):2660-2677. doi:10.1242/jeb.02292

Calduch-Giner JA, Mingarro M, de Celis SVR, Boujard D, Perez-Sanchez J (2003) Molecular cloning and characterization of gilthead sea bream, (Sparus aurata) growth hormone receptor (GHR). Assessment of alternative splicing. Comp Biochem Phys B 136 (1):1-13

Chen F, Chang D, Goh M, Klibanov SA, Ljungman M (2000) Role of p53 in cell cycle regulation and apoptosis following exposure to proteasome inhibitors. . Cell Growth Differ 11:239-246.

Chen J, Shi YH, Hu HQ, Niu H, Li MY (2009) Apolipoprotein A-I, a hyperosmotic adaptation-related protein in ayu (Plecoglossus altivelis). Comp Biochem Phys B 152 (2):196-201

Chmurzynska A (2006) The multigene family of fatty acid-binding proteins (FABPs): Function, structure and polymorphism. J Appl Genet 47:39-48

Cordeiro O, Silva T, Alves R, Costas B, Wulff T, Richard N, de Vareilles M, Conceição L, Rodrigues P (2012) Changes in Liver Proteome Expression of Senegalese Sole (\&lt;i\&gt;Solea senegalensis ) in Response to Repeated Handling Stress. Mar Biotechnol:1-16. doi:10.1007/s10126-012-9437-4

De la Torre FR, Ferrari L, Salibián A (2005) Biomarkers of a native fish species (Cnesterodon decemmaculatus) application to the water toxicity assessment of a peri-urban polluted river of Argentina. Chemosphere 59 (4):577-583. doi:10.1016/j.chemosphere.2004.12.039

De Smet H, Blust R (2001) Stress responses and changes in protein metabolism in carp Cyprinus carpio during cadmium exposure. Ecotoxicol Environ Saf 255$262 .: 255-262$.

Duttaroy A, Bourbeau D, Wang X-L, Wang E (1998) Apoptosis Rate Can Be Accelerated or Decelerated by Overexpression or Reduction of the Level of Elongation Factor-1a. Experimental Cell Research 238 (1):168-176. doi:10.1006/excr.1997.3819

EMEA (1997) Trimethoprim. Summary report (2). Committee for Veterianry Medical Products/ The European Agency for the Evaluation of Medical Products. Committee for Veterianry Medical Products. EMEA/MRL//255/97FINAL.

Eze LC (1983) Isoniazid inhibition of liver glutamic oxaloacetic transminase from the goat (Capra hircus). . Int J Biochem 15:13-16.

Furuhashi M, Hotamisligil GS (2008) Fatty acid-binding proteins: role in metabolic diseases and potential as drug targets. Nat Rev Drug Discov 7 (6):489-503

Gaudet M, Racicoot, J.C., Leray C (1975) Enzyme activities of plasma and selected tissues in rainbow trout, Salmo gairdneri. . J Fish Biol 505 - 512:505 - 512

Gonen H, Smith CE, Siegel NR, Kahana C, Merrick WC, Chakraburtty K, Schwartz AL, Ciechanover A (1994) Protein synthesis elongation factor EF-1 alpha is essential for ubiquitin-dependent degradation of certain $\mathrm{N}$ alpha-acetylated proteins and may be substituted for by the bacterial elongation factor EF-Tu. Proceedings of the National Academy of Sciences 91 (16):7648-7652 
Grondel JL, Nouws JFM, Haenen OLM (1986) Fish and antibiotics: Pharmacokinetics of sulphadimidine in carp (Cyprinus carpio). Veterinary Immunology and Immunopathology 12 (1-4):281-286

Hoang VM, Foulk R, Clauser K, Burlingame A, Gibson BW, Fisher SJ (2001) Functional Proteomics: Examining the Effects of Hypoxia on the Cytotrophoblast Protein Repertoire†. Biochemistry 40 (13):4077-4086. doi:10.1021/bi0023910

Hormazabal V, Rogstad A (1992) Simultaneous determination of sulphadiazine and trimethoprim in plasma and tissues of cultured fish for residual and pharmacokinetic studies. Journal of chromatography 583 (2):201-207

Horsberg TE, Martinsen B, Sandersen K, Zernichow L (1997) Potentiated sulfonamides: In vitro inhibitory effect and pharmacokinetic properties in atlantic salmon in seawater. Journal of Aquatic Animal Health 9 (3):203-210

Ibarz A, Martin-Perez M, Blasco J, Bellido D, de Oliveira E, Fernandez-Borras J (2010) Gilthead sea bream liver proteome altered at low temperatures by oxidative stress. Proteomics 10 (5):963-975. doi:10.1002/pmic.200900528

Inyang IR, Daka ER, Ogamba EN (2010) Effects of Sub-Lethal Concentrations of Diazinon on Total Protein and Transaminase Activities in Clarias gariepinus. Current Research Journal of Biological Sciences 2 (6):390-395

Johnston LD, Brown G, Gauthier D, Reece K, Kator H, Van Veld P (2008) Apolipoprotein A-I from striped bass (Morone saxatilis) demonstrates antibacterial activity in vitro. Comp Biochem Phys B 151 (2):167-175

Kleno TG, Leonardsen LR, Kjeldal HO, Laursen SM, Jensen ON, Baunsgaard D (2004) Mechanisms of hydrazine toxicity in rat liver investigated by Proteomics and multivariate data analysis. Proteomics 4 (3):868-880

Kleveland EJ, Ruyter B, Vegusdal A, Sundvold H, Berge RK, Gj' en T (2006) Effects of 3-thia fatty acids on expression of some lipid related genes in Atlantic salmon (Salmo salar L.). Comparative Biochemistry and Physiology Part B: Biochemistry and Molecular Biology 145 (2):239-248

Kosoff RE, Chen C-Y, Wooster GA, Getchell RG, Cliford A, Craigmill AL, Bowser PR (2007) Sulfadimethoxine and Ormetoprim residues in three species of fish after oral dosing in fed. Journal of Aquatic Animal Health 19:109-115

Liska AJ, Shevchenko A (2003) Expanding organismal scope of proteomics:crossspecies protein identification by mass spectrometry and its implications. Proteomics 3:19-28

Lunden T, Bylund G (2000) The influence of in vitro and in vivo exposure to antibiotics on mitogen-induced proliferation of lymphoid cells in rainbow trout (Oncorhynchus mykiss). Fish Shellfish Immun 10 (5):395-404

Lunden T, Bylund G (2002) Effect of sulphadiazine and trimethoprim on the immune response of rainbow trout (Oncorhynchus mykiss). Veterinary Immunology and Immunopathology 85 (1-2):99-108

Martin GG, Atshaves BP, Mclntosh AL, Mackie JT, Kier AB, Schroeder F (2006) Liver fatty acid binding protein gene ablation potentiates hepatic cholesterol accumulation in cholesterol-fed female mice. American Journal of Physiology Gastrointestinal and Liver Physiology 290 (1):G36-G48. doi:10.1152/ajpgi.00510.2004

Martin GG, Danneberg H, Kumar LS, Atshaves BP, Erol E, Bader M, Schroeder F, Binas B (2003) Decreased Liver Fatty Acid Binding Capacity and Altered Liver Lipid Distribution in Mice Lacking the Liver Fatty Acid-binding Protein Gene. Journal of Biological Chemistry 278 (24):21429-21438. doi:10.1074/jbc.M300287200

Nilsson GE (1988) A comparative study of aldehyde dehydrogenase and alcohol dehydrogenase activities in crucian carp and three other vertebrates: apparent adaptations to ethanol production. Journal of Comparative Physiology B: 
Biochemical, Systemic, and Environmental Physiology 158 (4):479-485. doi:10.1007/bf00691145

Nowell MA, Power DM, Guerreiro PM, Llewellyn L, Ramsurn V, Wigham T, Sweeney GE (2000) Cloning and expression of an elongation factor-1a in sea bream (Sparus aurata) larvae and adult tissue. Mar Biotechnol 2 (2):173-179

Pakas SM, Dickey RW, Barron MG, Guarino AM (1990) Tissue distribution and renal excretion of ormetoprim after intravascular and oral administration in the chanel catfish (Ictalurus punctatus). Can J Fish Aquat Sci 47:766-771

Prashanth MS, Neelagund SE (2008) Impact of Cypermethrin on enzyme activities in the freshwater fish Cirrhinus mrigala (Hamilton). Caspian Journal of Environmental Sciences 6 (2):91-95

Pretti C, Salvetti A, Longo V, Giorgi M, Gervasi PG (2001) Effects of betanaphthoflavone on the cytochrome P450 system, and phase II enzymes in gilthead seabream (Sparus aurata). Comp Biochem Physiol C-Toxicol Pharmacol 130 (1):133-144. doi:10.1016/s1532-0456(01)00231-9

Rigos G, Katharios P (2009) Pathological obstacles of newly-introduced fish species in Mediterranean mariculture: a review. Rev Fish Biol Fisheries 20 (1):47-70. doi:DOI 10.1007/s11160-009-9120-7

Rigos G, Troisi GM (2005) Antibacterial Agents in Mediterranean Finfish Farming: A Synopsis of Drug Pharmacokinetics in Important Euryhaline Fish Species and Possible Environmental Implications. Reviews in fish Biology and Fisheries 15 (1-2):53-73. doi:10.1007/s11160-005-7850-8

Rufino-Palomares E, Reyes-Zurita FJ, Fuentes-Almagro CA, de la Higuera $M$, Lupianez JA, Peragon J (2011) Proteomics in the liver of gilthead sea bream (Sparus aurata) to elucidate the cellular response induced by the intake of maslinic acid. Proteomics 11 (16):3312-3325. doi:10.1002/pmic.201000271

Saglam N, Yonar ME (2009) Effects of sulfamerazine on selected haematological and immunological parameters in rainbow trout (Onchorhynchus mykiss, Walbaum, 1792). Aquaculture Research 40 (4):395-404

Salas-Leiton E, Canovas-Conesa B, Zerolo R, Lopez-Barea J, Canavate JP, Alhama J (2009) Proteomics of Juvenile Senegal Sole (Solea senegalensis) Affected by Gas Bubble Disease in Hyperoxygenated Ponds. Mar Biotechnol 11 (4):473487

Samuelsen OB, Pursell L, Smith P, Ervik A (1997) Multiple-dose pharmacokinetic study of Romet30 in Atlantic salmon (Salmo salar) and in vitro antibacterial activity against Aeromonas salmonicida. Aquaculture 152 (1-4):13-24

Scott P (1993) Therapy in aquaculture. In: Brown L (ed) Aquaculture for veterinarians. Pergamon Press Oxford, pp 131-153

Shevchenko A, Jensen ON, Podtelejnikov AV, Sagliocco F, Wilm M, Vorm O, Mortensen P, Shevchenko A, Boucherie H, Mann M (1996) Linking genome and proteome by mass spectrometry: Large-scale identification of yeast proteins from two dimensional gels. P Natl Acad Sci USA 93 (25):14440-14445

Varo I, Rigos G, Navarro JC, del Ramo J, Calduch-Giner J, Hernandez A, Pertusa J, Torreblanca A (2010) Effect of ivermectin on the liver of gilthead sea bream Sparus aurata: a proteomic approach. Chemosphere 80 (5):570-577. doi:10.1016/j.chemosphere.2010.04.030

Vasiliou V, Pappa A, Petersen DR (2000) Role of aldehyde dehydrogenases in endogenous and xenobiotic metabolism. Chemico-Biological Interactions 129 (1-2):1-19. doi:10.1016/s0009-2797(00)00211-8

Veiseth-Kent E, Grove H, Faergestad EM, Fjaera SO (2010) Changes in muscle and blood plasma proteomes of Atlantic salmon (Salmo salar) induced by crowding. Aquaculture 309 (1-4):272-279. doi:10.1016/j.aquaculture.2010.09.028

Villarroel F, Bastias A, Casado A, Amthauer R, Concha MI (2007) Apolipoprotein A-I, an antimicrobial protein in Oncorhynchus mykiss: Evaluation of its expression in 
primary defence barriers and plasma levels in sick and healthy fish. Fish Shellfish Immun 23 (1):197-209

Wang G, Gong Y, J. A, Sun D, Minuk G, Roberts MS, Burczynski FJ (2005) Antioxidative function of L-FABP in L-FAPB stably transfected Chang liver cells. Hepatology 42:871-879

Wang J, Wei Y, Wang D, Chan L, Dai J (2008) Proteomic study of the effects of complex environmental stresses in the livers of goldfish ( \&lt;i\&gt;Carassius auratus ) that inhabit Gaobeidian Lake in Beijing, China. Ecotoxicology (London, England) 17 (3):213-220. doi:10.1007/s10646-007-0187-4

Wang P, Bouwman FG, Mariman ECM (2009) Generally detected proteins in comparative proteomics - A matter of cellular stress response Proteomics 9 (11):2955-2966. doi:10.1002/pmic.200800826

Waridel P, Frank A, Thomas H, Surendranath V, Sunyaev S, Pevzner P, Shevchenko A (2007) Sequence similarity-driven proteomics in organisms with unknown genomes by LC-MS/MS and automated de novo sequencing. Proteomics 7 (14):2318-2329. doi:10.1002/pmic.200700003

Waterfield CJ, Asker DS, Timbrell JA (1997) Triglyceride disposition in isolated hepatocytes after treatment with hydrazine Chem Biol Interact 107:157-172

Wulff T, Jessen F, Roepstorff P, Hoffmann EK (2008) Long term anoxia in rainbow trout investigated by 2-DE and MS/MS. Proteomics 8 (5):1009-1018. doi:10.1002/pmic.200700460

Yildiz HY, Altunay S (2011) Physiologycal stress and innate immune response in gilthead sea bream (Sparus aurata) and sea bass (Dicentrarchus labrax) exposed to combination of trimethoprim and sulfamethoxazole (TMP-SMX). Fish PhysiolBiochem 37 (3):401-409 
Table 1. Forward and reverse primers used in the real-time quantitative PCR assay.

\begin{tabular}{|c|c|c|c|c|}
\hline Gene & $\begin{array}{c}\text { Accession } \\
\text { number }\end{array}$ & & Primer sequence & Position \\
\hline $\begin{array}{l}\text { Apolipoprotein } \\
\text { A-1 }\end{array}$ & AF013120 & $\begin{array}{l}\mathrm{F} \\
\mathrm{R}\end{array}$ & $\begin{array}{l}\text { GAA TAC AAG GAG CAG ATG AAG CAG ATG } \\
\text { TGG TGA CGG AGG CAG CGA TG }\end{array}$ & $\begin{array}{l}664-690 \\
808-789\end{array}$ \\
\hline $\begin{array}{l}\text { Mitochondrial } \\
\text { aldehyde } \\
\text { dehydrogenase }\end{array}$ & HQ228168 & $\begin{array}{l}\mathrm{F} \\
\mathrm{R}\end{array}$ & $\begin{array}{l}\text { CCA TCC CAG CAC CCA ACA CC } \\
\text { CCT CAT CAG CCT CAG CCA CTT G }\end{array}$ & $\begin{array}{l}135-154 \\
284-263\end{array}$ \\
\hline $\begin{array}{l}\text { Phosphoglucomu } \\
\text { tase } 1\end{array}$ & HQ228169 & $\begin{array}{l}\mathrm{F} \\
\mathrm{R}\end{array}$ & $\begin{array}{l}\text { ACT CCG CCG TCA ACT GTG TC } \\
\text { CCA GGT CAG CAG CGT AGG TC }\end{array}$ & $\begin{array}{l}265-284 \\
345-326\end{array}$ \\
\hline $\begin{array}{l}\text { Fatty acid- } \\
\text { binding protein }\end{array}$ & HQ228170 & $\begin{array}{l}\mathrm{F} \\
\mathrm{R}\end{array}$ & $\begin{array}{l}\text { AAA TGG TTG AGG CTT TCT GTG CTA C } \\
\text { ATC GCT ACT GTC GGC TTG GTG }\end{array}$ & $\begin{array}{l}48-72 \\
177-157\end{array}$ \\
\hline $\begin{array}{l}\text { Elongation Factor } \\
1\end{array}$ & AF184170 & $\begin{array}{l}\mathrm{F} \\
\mathrm{R}\end{array}$ & $\begin{array}{l}\text { CCC GCC TCT GTT GCC TTC G } \\
\text { CAG CAG TGT GGT TCC GT }\end{array}$ & $\begin{array}{l}560-578 \\
694-674\end{array}$ \\
\hline a-Tubulin & AY326430 & $\begin{array}{l}\mathrm{F} \\
\mathrm{R}\end{array}$ & $\begin{array}{l}\text { GAC ATC ACC AAT GCC TGC TTC } \\
\text { GTG GCG ATG GCG GAG TTC }\end{array}$ & $\begin{array}{l}514-534 \\
647-630\end{array}$ \\
\hline
\end{tabular}


Table 2 - Protein identities differentially expressed in the gilthead seabream (Sparus aurata) liver after treatment with SDZ/TMP for 10 days. $p$-value represents the significance level of t-test performed by the image analysis software DeCyder of up or down regulated spots.

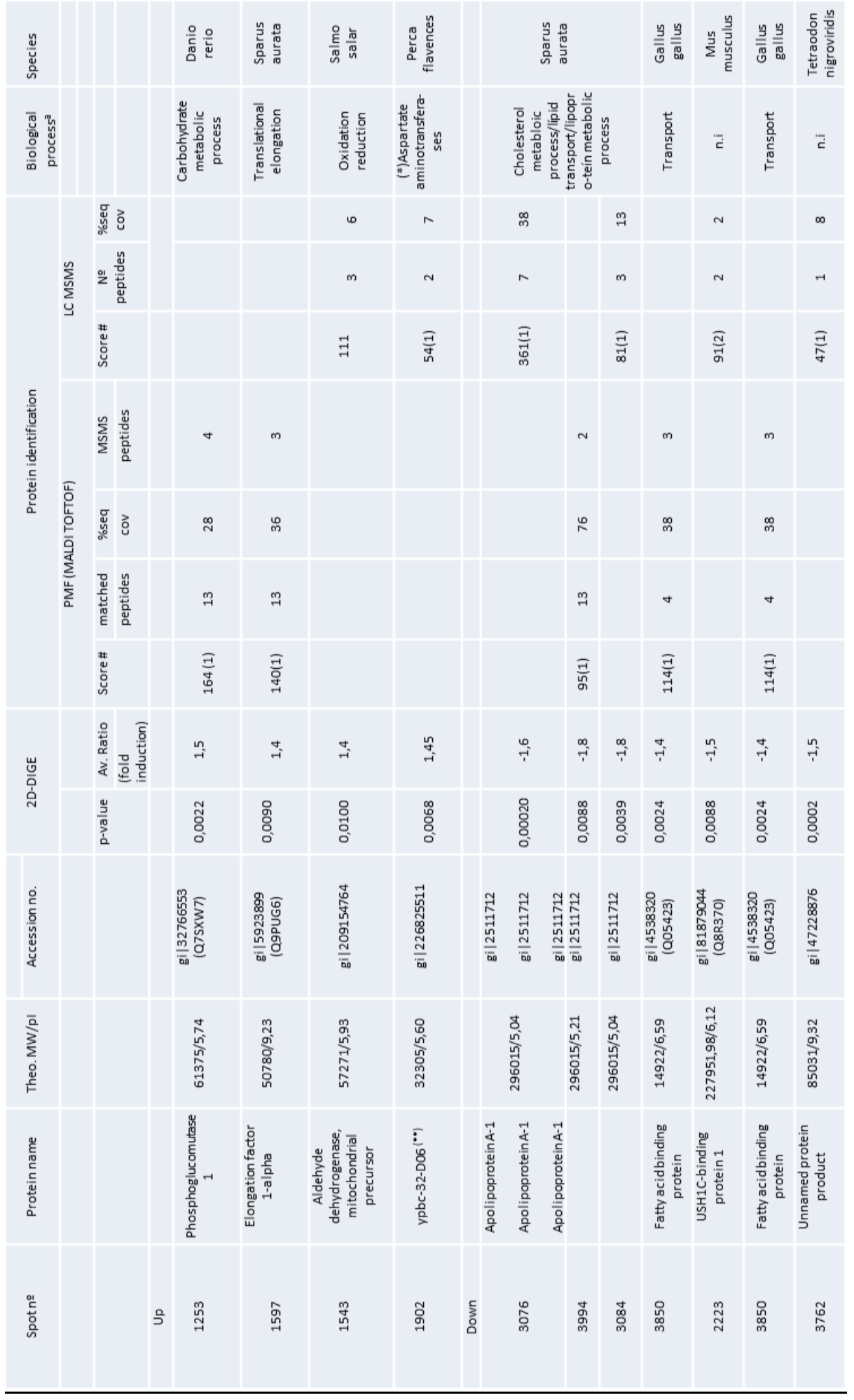

Accession $n \div$ : NCB $\mathrm{n}^{\circ}$ (UniProt $\mathrm{n} \div$ )

Protein identification: (1)PMF $=(\mathrm{MALDI}),(2) \mathrm{MSMS}=(\mathrm{Q}-\mathrm{Star})$

$\left({ }^{a}\right)$ Biological process according to Gene Ontology (UNiProtKB GO); n.i., non indientified; $\left({ }^{*}\right)$ BLAST NCBI fro gene; $\left({ }^{* *}\right)$ EST data base 
Fig. 1

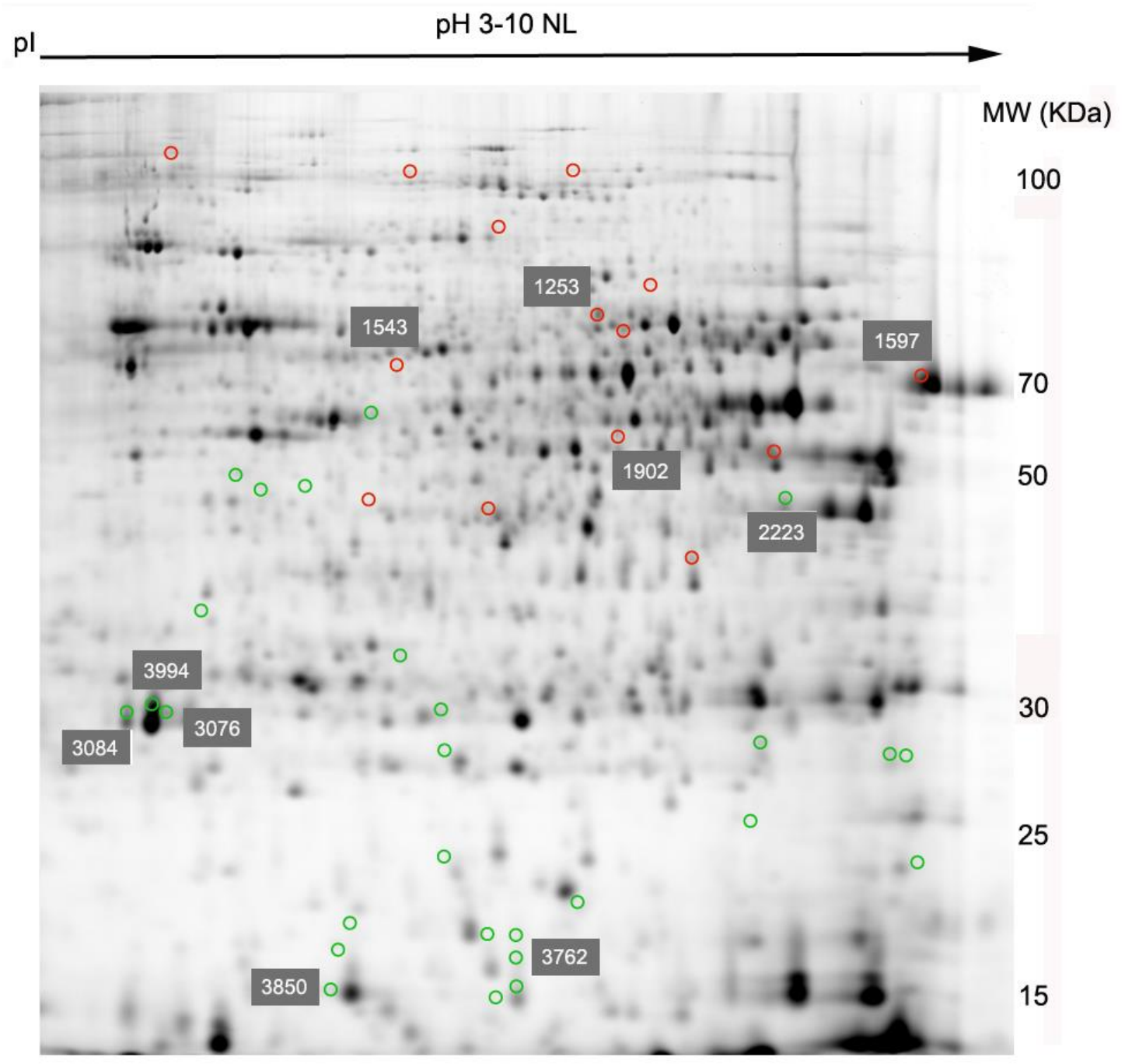


Fig. $2(\mathrm{~A})$

Spot Maps (Score Plot)



Fig. $2(\mathrm{~B})$




Fig 3

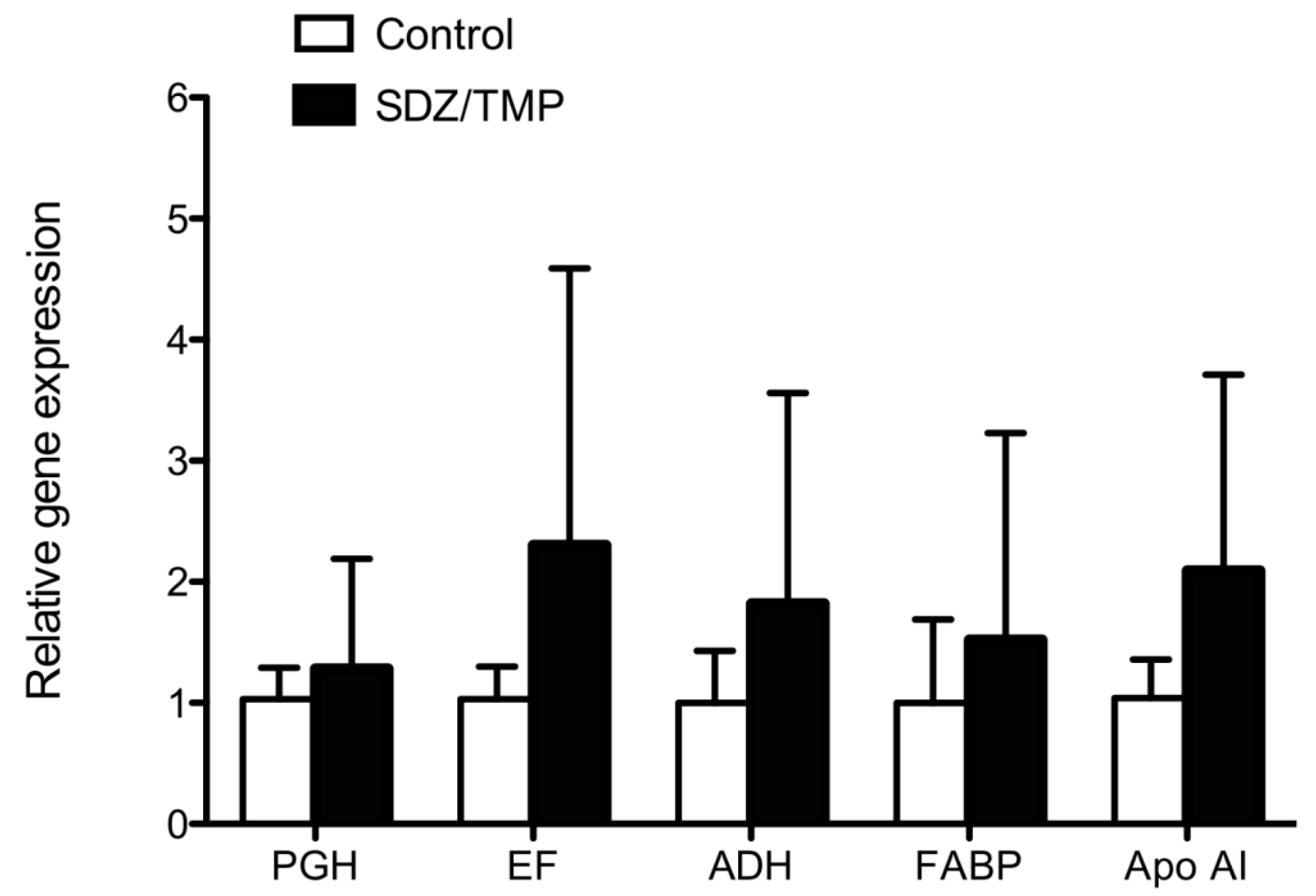


Fig. 4






